\title{
Indications of Cardiac Resynchronization in Non-Left Bundle Branch Block: Clinical Review of Available Evidence
}

\author{
Maged Henin ${ }^{\mathrm{a}}$, Hany Ragy ${ }^{\mathrm{b}}$, James Mannion ${ }^{\mathrm{a}}$, Santhosh David ${ }^{\mathrm{c}}$, \\ Beshoy Refila ${ }^{\mathrm{d}}$, Usama Boles ${ }^{\mathrm{d}, \mathrm{e}}$
}

\begin{abstract}
Cardiac resynchronization therapy (CRT) benefits have been firmly established in patients with heart failure and reduced left ventricular ejection fraction (HFrEF), who remain in New York Heart Association (NYHA) functional classes II and III, despite optimal medical therapy, and have a wide QRS complex. An important and consistent finding in published systematic reviews and in subgroup analyses is that the benefits of CRT are maximum for patients with a broader QRS durations, typically described as QRS duration > $150 \mathrm{~ms}$, and for patients with a typical left bundle branch block (LBBB) QRS morphology. It remains uncertain whether patients with non-LBBB QRS complex morphology clearly benefit from CRT or only modestly respond.
\end{abstract}

Keywords: Non-LBBB; RBBB; Typical LBBB; HFrEF: Cardiac resynchronization therapy; QRS duration

\section{Introduction}

Cardiac resynchronization therapy (CRT) benefits have been firmly established in patients with heart failure and reduced left ventricular ejection fraction (HFrEF), who remain in New York Heart Association (NYHA) functional classes II and III despite optimal medical therapy, and have a wide QRS complex [1]. An important and consistent finding in published systematic reviews and in subgroup analyses is that the benefits of CRTs are maximum for patients with a broader QRS durations, typically described as QRS duration $>150 \mathrm{~ms}$, and for patients with a typical left bundle branch block (LBBB) QRS morphology [2]. It remains uncertain whether patients with non-LBBB

Manuscript submitted November 19, 2019, accepted December 16, 2019

aUniversity Hospital Waterford, Waterford, Ireland

bNational Heart Institute, Cairo, Egypt

${ }^{\mathrm{c} C a r d i o l o g y}$ Department, Letterkenny University Hospital, Donegal, Ireland

${ }^{\mathrm{d} C}$ Cardiology Department, Heart and Vascular Center, Mater Private Hospital, Dublin 7, Ireland

${ }^{e}$ Corresponding Author: Usama Boles, Heart and Vascular Center, Mater Private Hospital, 72 Eccles Street, Dublin 7, Ireland. Email: bolesu@tcd.ie

doi: https://doi.org/10.14740/cr989
QRS complex morphology clearly benefit from CRT or only modestly respond [3-6].

In this article, we reviewed the major trials that enriched the most recent international guidelines for CRT implantation focusing on the available data about the outcome of using CRT in non-LBBB cohort. Furthermore, we conferred the current guidelines, including the comprehensive update of the Canadian Cardiovascular Society (CCS) guidelines for the management of heart failure (HF) 2017 [2], the European Society of Cardiology (ESC) Heart Failure Association guidelines for the diagnosis and treatment of acute and chronic HF 2016 [7], the National Institute of Health and Care Excellence (NICE) guidelines for ICD (implantable cardioverter defibrillator) and CRT for arrhythmia and heart failure 2014 [8], the American College of Cardiology Foundation/American Heart Association guideline for the management of heart failure 2013 [9], the ESC European Heart Rhythm Association guidelines on cardiac pacing and cardiac resynchronisation therapy 2013 [10], and the update to National Heart Foundation of Australia and Cardiac Society of Australia and New Zealand guidelines for the prevention, detection and management of chronic HF in Australia 2011 [11].

\section{The Non-LBBB Wide QRS Complex Electrocar- diogram (ECG) Criteria}

Non-LBBB wide QRS complex patterns include the following four groups are represented in Figure 1 as follow: 1) Atypical LBBB represent "QRS duration greater than or equal to 120 $\mathrm{ms}$ in adults, broad notched or slurred $\mathrm{R}$ wave in leads $\mathrm{I}$, aVL, $\mathrm{V} 5$, and V6, and an occasional RS pattern in V5 and V6 attributed to displaced transition of QRS complex, absent q waves in leads I, V5, and V6, and R peak time greater than $60 \mathrm{~ms}$ in leads V5 and V6" with atypical feature such as Q wave in I and aVL, larger R wave in V1 and V2, or V6 QRS complex morphology which is different from those in I and aVL (Fig. 1a). 2) Complete (typical) right bundle branch block (RBBB) is described as QRS duration $\geq 120 \mathrm{~ms}$ in adults, rsr', rsR', or $\mathrm{rSR}^{\prime}$ in leads V1 or V2, R or $\mathrm{r}$ deflection is usually wider than the initial $\mathrm{R}$ wave patients, $\mathrm{S}$ wave of greater duration than $\mathrm{R}$ wave or greater than $40 \mathrm{~ms}$ in leads I and V6 in adults, and normal $\mathrm{R}$ peak time in leads V5 and V6 but $>50 \mathrm{~ms}$ in lead V (Fig. 1b). 3) Interventricular conduction delay (IVCD) which characterized by wide QRS morphology that does not resem- 

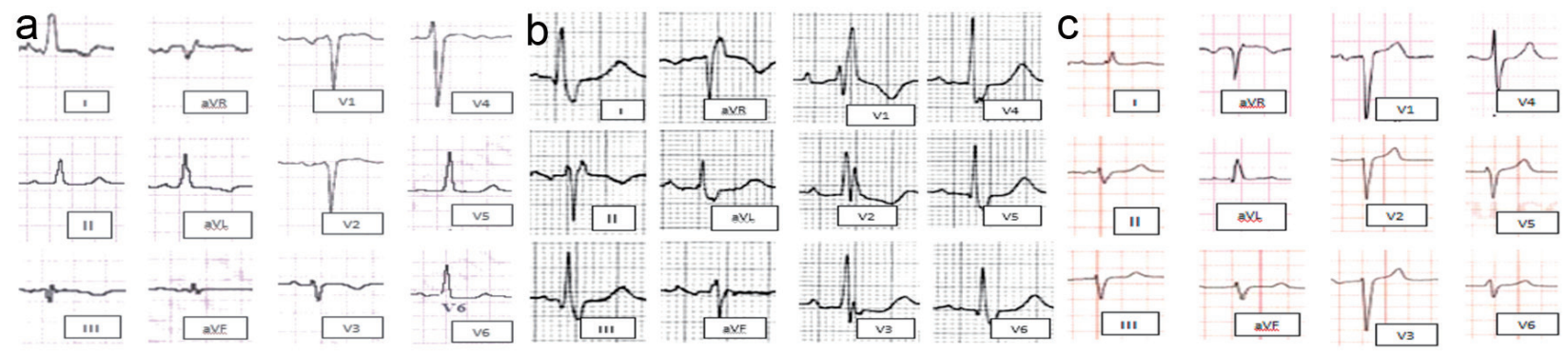

Figure 1. Different ECG morphological pattern of non-LBBB wide QRS complex. (a) Atypical LBBB. (b) Typical RBBB. (c) Nonspecific interventricular conduction block. ECG: electrocardiogram; LBBB: left bundle branch block; RBBB: right bundle branch block.

ble either typical LBBB or RBBB. The definition may also be applied to a pattern with RBBB criteria in the precordial leads and $\mathrm{LBBB}$ criteria in the limb leads, and vice versa (Fig. 1c). 4) Atypical RBBB may represent underlying delay in left ventricular (LV) activation as well. RBBB masks the underlying co-existent LBBB in broader QRS indicating advanced grade of dyssynchrony (Fig. 2) [12].

The ECG morphological patterns of atypical LBBB, typical RBBB and IVCD ECGs are illustrated in Figure 1. The atypical RBBB ECG is illustrated in Figure 2.

\section{Indications of CRT in Non-LBBB QRS Morphol- ogy in the Landmark Clinical Trials}

Over last decade, 13 major studies, involving the outcomes of CRT use in patients with HFrEF, were conducted between 2002 and 2018 (Table 1, [13-25]). Remarkably, from 2002 to 2010, the ECG selection criteria were based solely on prolonged QRS duration without differentiation between types of bunch branch block morphology [13-23]. On the other hand, the ENHANCE CRT pilot study (2018) was conducted solely in such "non-LBBB" patients to investigate the advantage of
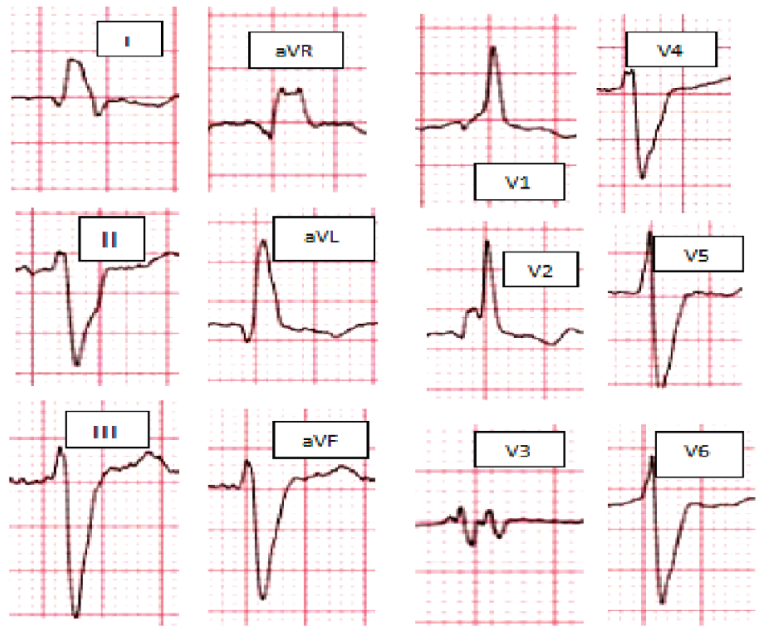

Figure 2. Atypical RBBB: broad, slurred, and notched $R$ wave on leads I and aVL, together with a leftward axis deviation. RBBB: right bundle branch block. using an electrophysiologic measure of left ventricular (LV) delay to guide lead placement when implanting the CRT's biventricular lead system [25].

Until 2015, the major trials lacked the evidence that nonLBBB patients as a group would benefit from CRT implantation. The MIRACLE ICD trial stated that the benefit of CRT was positive regardless of QRS morphology although they admit they may have been underpowered in this regard [16].

Investigators of the COMPANION trial did a subgroup univariate analysis on factors associated with hospitalization risk for all patients in RBBB and/or IVCD and compared to LBBB, which produced clear evidence that the benefit of CRT was mainly observed in patients with LBBB (hazard ratio (HR) of 1.26). Similarly, IVCD was compared to RBBB or LBBB yielding a similar outcome (HR of 1.24) [22]. However, RAFT trial had comparable outcomes $(\mathrm{HR}=1)$ [23].

The MADIT-CRT trial stated that the benefits from CRT among the trial's patients without LBBB were not the same as LBBB patients, and in fact it suggested CRT might increase their mortality [20]. However, recently in 2018, the ENHANCE CRT study, the first head-to-head comparison of additional LV lead placement guided by electrical delay versus the standard of care, concluded that CRT is an effective therapy in patients with non-LBBB with no apparent distinction seen in responses by subgroups, including RBBB vs. IVCD, QRS interval, sex, HF cause, or left ventricular ejection fraction (LVEF). In addition, there were no significant differences between the two interventional arms in quality of life or LVEF [25]. The earlier trials finding of possible harm in non-LBBB are less relevant to this study as the included patients were in softer indications (i.e. NYHA class I to II in MADIT-CRT versus III to IV in ENHANCE CRT).

\section{Guidelines and Recommendations for CRT in Non-LBBB QRS Morphology}

ACC/AHA/HRS, ESC, and CCS guidelines agree that if a patient has a QRS duration $>150 \mathrm{~ms}$ and is in NYHA functional class III or ambulatory IV, then a CRT "better to be considered" (class IIa). When QRC duration is $<150 \mathrm{~ms}$, there is considerable inconsistency in the guidelines. Both ACC/AHA/ HRS and ESC guidelines favor the CRT (class IIb), however the CCS guidelines do not provide a formal recommendation 
Table 1. Summary of the CRT Landmark Clinical Trials

\begin{tabular}{|c|c|c|c|c|}
\hline Study & Aim & $\begin{array}{l}\text { Patients and ran- } \\
\text { domization }\end{array}$ & QRS complex pattern & Results \\
\hline $\begin{array}{l}\text { Path CHF, Auricchio } \\
\text { et al, } 2002[13]\end{array}$ & $\begin{array}{l}\text { Compare the short- } \\
\text { and long-term } \\
\text { clinical effects of } \\
\text { atrial synchronous, } \\
\text { pre-excitation of } \\
\text { univentricular or } \\
\text { biventricular therapy } \\
\text { with cardiac CRT. }\end{array}$ & $\begin{array}{l}\mathrm{N}=42 \text {; randomized to } \\
\text { biventricular CRT (24)/ } \\
\text { univentricular CRT (17); } \\
\text { followed for } 9 \text { months }\end{array}$ & $\begin{array}{l}\text { QRS } \geq 120 \mathrm{~ms} ; \\
\mathrm{LBBB}, 39(93 \%) / \\
\mathrm{RBBB}, 3(7 \%)\end{array}$ & $\begin{array}{l}\text { CRT produces a long-term } \\
\text { improvement in the clinical } \\
\text { symptoms of patients with HF } \\
\text { who have significant IVCD. }\end{array}$ \\
\hline $\begin{array}{l}\text { MIRACLE, Abraham } \\
\text { et al, } 2002[14]\end{array}$ & $\begin{array}{l}\text { Evaluate the clinical } \\
\text { benefit of CRT in } \\
\text { symptomatic heart } \\
\text { failure with IVCD. }\end{array}$ & $\begin{array}{l}\mathrm{N}=453 \text {; randomized } \\
\text { to CRT group (228)/ } \\
\text { control (225); followed } \\
\text { for } 6 \text { months }\end{array}$ & $\mathrm{QRS} \geq 130 \mathrm{~ms}$ & $\begin{array}{l}\text { Significant clinical improvement } \\
\text { in moderate to severe heart } \\
\text { failure with IVCD. }\end{array}$ \\
\hline $\begin{array}{l}\text { CONTAK CD, } \\
\text { Higgins et al, } \\
2003[15]\end{array}$ & $\begin{array}{l}\text { Assess the safety } \\
\text { and effectiveness of } \\
\text { cardiac CRT when } \\
\text { combined with an ICD. }\end{array}$ & $\begin{array}{l}\mathrm{N}=490 \text {; randomized to } \\
\text { CRT }(245) / \text { control }(245) \\
\text { followed for } 6 \text { months }\end{array}$ & $\begin{array}{l}\text { QRS } \geq 120 \mathrm{~ms} ; \text { CRT } \\
\text { group: LBBB 50\%/ } \\
\text { NSIVCD } 32 \% / \text { RBBB } \\
\text { 18\%; non-CRT group: } \\
\text { LBBB 54\%/NSIVCD } \\
34 \% / \text { RBBB } 12 \%\end{array}$ & $\begin{array}{l}\text { CRT implant has improved the } \\
\text { functional status in all patients } \\
\text { that were indicated for ICD } \\
\text { and have HFrEF and IVCD. }\end{array}$ \\
\hline $\begin{array}{l}\text { MIRACLE } \\
\text { ICD, Young et } \\
\text { al, } 2003[16]\end{array}$ & $\begin{array}{l}\text { Examine the efficacy } \\
\text { and safety of combined } \\
\text { CRT and ICD therapy } \\
\text { in patients with NYHA } \\
\text { class III or IV CHF } \\
\text { despite appropriate } \\
\text { medical management. }\end{array}$ & $\begin{array}{l}\mathrm{N}=369 ; \text { randomized } \\
\text { to CRT on }(187) / \mathrm{CRT} \\
\text { off }(182) \text {; followed } \\
\text { for } 6 \text { months }\end{array}$ & $\begin{array}{l}\text { QRS } \geq 130 \mathrm{~ms} ; \text { CRT } \\
\text { group: LBBB } 87 \% / \\
\text { RBBB } 13 \% ; \text { control } \\
\text { group: LBBB } 86 \% / \\
\text { RBBB } 14 \%\end{array}$ & $\begin{array}{l}\text { CRT improved quality of life, } \\
\text { functional status, and exercise } \\
\text { capacity in patients with } \\
\text { moderate to severe HF, a wide } \\
\text { QRS interval, and life-threatening } \\
\text { arrhythmias. CRT effect on QOL } \\
\text { score and NYHA functional } \\
\text { class was not influenced by } \\
\text { morphology of the BBB (R vs. L) }\end{array}$ \\
\hline $\begin{array}{l}\text { REVERSE, Linde } \\
\text { et al, 2008 [19] }\end{array}$ & $\begin{array}{l}\text { Assess the effects of } \\
\text { CRT use in patients } \\
\text { with NYHA functional } \\
\text { class I and II. }\end{array}$ & $\begin{array}{l}\mathrm{N}=610 \text {; randomized } \\
\text { to CRT group }(419) / \\
\text { control }(191) ; \text { followed } \\
\text { for } 12 \text { months }\end{array}$ & $\mathrm{QRS} \geq 120 \mathrm{~ms}$ & $\begin{array}{l}\text { CRT in combination with } \\
\text { optimal medical therapy } \\
(+/ \text {-defibrillator), reduces the } \\
\text { risk for HF hospitalization and } \\
\text { improves ventricular structure } \\
\text { and function in NYHA I and II. }\end{array}$ \\
\hline $\begin{array}{l}\text { MADIT CRT, } \\
\text { Breithardt et al, } \\
2009[20]\end{array}$ & $\begin{array}{l}\text { Determine whether } \\
\text { CRT with biventricular } \\
\text { pacing would reduce } \\
\text { the risk of death or HF } \\
\text { events in patients with } \\
\text { NYHA I or II, reduced } \\
\text { EF of } \leq 30 \% \text { and QRS } \\
\text { duration } \geq 130 \mathrm{~ms} \text {. }\end{array}$ & $\begin{array}{l}\mathrm{N}=1,820 ; \text { randomized to } \\
\text { CRT (CRT and ICD on) } \\
\text { group }(1,089) / \text { control (CRT } \\
\text { off and ICD on) }(731) \text {; } \\
\text { followed for up of } 2.4 \text { years }\end{array}$ & $\begin{array}{l}\text { QRS } \geq 130 \mathrm{~ms} ; \\
\text { CRT group: LBBB } \\
\text { (761)/RBBB }(136) ; \\
\text { control: LBBB } \\
(520) / \text { RBBB }(92)\end{array}$ & $\begin{array}{l}\text { CRT combined with ICD } \\
\text { decreased the risk of HF events } \\
\text { in relatively asymptomatic } \\
\text { patients with a low ejection } \\
\text { fraction and wide QRS complex. }\end{array}$ \\
\hline
\end{tabular}


Table 1. Summary of the CRT Landmark Clinical Trials - (continued)

\begin{tabular}{|c|c|c|c|c|}
\hline Study & Aim & $\begin{array}{l}\text { Patients and ran- } \\
\text { domization }\end{array}$ & QRS complex pattern & Results \\
\hline $\begin{array}{l}\text { REVERSE, Daubert } \\
\text { et al, } 2009 \text { [21] }\end{array}$ & $\begin{array}{l}\text { Evaluate the long-term } \\
\text { effects of CRT in the } \\
\text { European cohort of } \\
\text { patients enrolled in } \\
\text { the REVERSE trial. }\end{array}$ & $\begin{array}{l}\mathrm{N}=262 \text {, randomized to } \\
\text { CRT group (ICD activated, } \\
\text { CRT on) (180)/control (ICD } \\
\text { activated, CRT off) }(82) ; \\
\text { followed for } 24 \text { months }\end{array}$ & $\mathrm{QRS} \geq 120 \mathrm{~ms}$ & $\begin{array}{l}\text { Clinical functional outcomes } \\
\text { improved and LV end systolic } \\
\text { volume decreased by a greater } \\
\text { mean in CRT on than CRT off. } \\
\text { First HF hospitalization or death } \\
\text { was significantly delayed by } \\
\text { CRT (HR: } 0.38 ; \mathrm{P}=0.003 \text { ). }\end{array}$ \\
\hline $\begin{array}{l}\text { COMPANION, } \\
\text { Anand et al, } \\
2009[22]\end{array}$ & $\begin{array}{l}\text { Assess the use of } \\
\text { CRT as a treatment } \\
\text { of CHF on mortality } \\
\text { and hospitalization. }\end{array}$ & $\begin{array}{l}\mathrm{N}=1,520 ; \text { randomized } \\
\text { in 1:2:2 ratios for optimal } \\
\text { medical management }(308) / \\
\text { CRT-p }(617) / C R T-d(595) ; \\
\text { followed for } 15 \text { months }\end{array}$ & $\mathrm{QRS} \geq 120 \mathrm{~ms}$ & $\begin{array}{l}\text { CRT pacing with or without ICD } \\
\text { capability was associated with } \\
\text { a significant } 1 \text {-year relative risk } \\
\text { reduction of about } 20 \% \text { for all- } \\
\text { cause death or hospitalization. }\end{array}$ \\
\hline $\begin{array}{l}\text { RAFT, Tang et } \\
\text { al, } 2010 \text { [23] }\end{array}$ & $\begin{array}{l}\text { Evaluate whether CRT } \\
\text { benefits patients with } \\
\text { LV systolic dysfunction } \\
\text { and a wide QRS. }\end{array}$ & $\begin{array}{l}\mathrm{N}=1,798 \text {; randomized to } \\
\text { CRT group (ICD activated, } \\
\text { CRT on) (894)/control (ICD } \\
\text { activated, CRT off) (904); } \\
\text { followed up for } 40 \text { months }\end{array}$ & $\begin{array}{l}\text { QRS } \geq 120 \text { ms; CRT } \\
\text { group: LBBB72.9\%/ } \\
\text { NIVCD } 11.9 \% / \\
\text { RBBB } 7.6 \% \text {; control } \\
\text { group: LBBB71.1\%/ } \\
\text { NIVCD } 11.2 \% / \\
\text { RBBB } 7.4 \%\end{array}$ & $\begin{array}{l}\text { The combined use of CRT } \\
\text { with ICD has reduced the } \\
\text { mortality and hospitalization } \\
\text { for HF patients. }\end{array}$ \\
\hline $\begin{array}{l}\text { BLOCK HF, Curtis } \\
\text { et al, } 2016 \text { [24] }\end{array}$ & $\begin{array}{l}\text { Assess biventricular } \\
\text { pacing against primary } \\
\text { end points of reduce } \\
\text { mortality, morbidity, } \\
\text { and adverse left } \\
\text { ventricular remodeling } \\
\text { in patients with high } \\
\text { grade AV block; and } \\
\text { NYHA class I, II, } \\
\text { or III; and a LVEF } \\
\text { of } 50 \% \text { or less. }\end{array}$ & $\begin{array}{l}\mathrm{N}=691 \text {; randomized } \\
\text { to Biventricular pacing } \\
(349) / \mathrm{RV} \text { pacing }(342) \text {; } \\
\text { followed for } 24 \text { months }\end{array}$ & $\begin{array}{l}\text { QRS } \geq 120 \mathrm{~ms} ; \\
\text { biventricular pacing: } \\
\text { 1st AV block }(68) / 2 \text { nd } \\
\text { AV block }(119) / 3 \text { rd AV } \\
\text { block 162/LBBB (123)/ } \\
\text { RBBB (73); RV pacing: } \\
\text { 1st AV block }(66) / 2 \text { nd } \\
\text { AV block }(108) / 3 \text { rd } \\
\text { AV block }(167) / L B B B \\
(102) / \text { RBBB }(74)\end{array}$ & $\begin{array}{l}\text { Biventricular pacing was superior } \\
\text { to conventional right ventricular } \\
\text { pacing alone in patients with } \\
\text { AV block and left ventricular } \\
\text { systolic dysfunction with } \\
\text { NYHA class I, II, or III HF. }\end{array}$ \\
\hline
\end{tabular}

The table summarized all landmark trials influencing CRT guidelines since 2002. Most of these trials do not have any subgroup analysis of patients with non-LBBB. The trials consist of patients of varying classes of NYHA, using different endpoints such as rehospitalization or mortality, the cohort however is primarily LBBB or non-specified QRS prolongation. CHF: congestive heart failure; CRT: cardiac resynchronization therapy; NYHA: New York Heart Association; ICD: implantable cardioverter defibrillator; IVCD: intraventricular conduction delay; NSIVCD: nonspecific interventricular conduction delay; LVEF: left ventricular ejection fraction; LBBB: left bundle branch block; RBBB: right bundle branch block; QOL: quality of life; HFrEF: heart failure with reduced ejection fraction; LBFB: left posterior fascicular block; LAFB: left anterior fascicular block; LV: left ventricular; RV: right left ventricular; AV: atrioventricular.

for this patient group; instead, they simply state that there is no clear evidence of benefit with CRT among patients with QRS duration $<150 \mathrm{~ms}$ because of non-LBBB conduction.

NICE guidelines recommend CRT device insertion in patients with non-LBBB QRS morphology, who have QRS duration $\geq 150 \mathrm{~ms}$ and in NYHA functional classes II, III, and IV.
CRT pacemaker without ICD insertion is indicated in patients with non-LBBB QRS morphology who have a QRS between 120 and $149 \mathrm{~ms}$ and in NYHA functional class IV. NICE guidelines also provide a clear guidance on whether to implant a cardiac resynchronization therapy with pacemaker (CRT-P) or a cardiac resynchronization therapy defibrillator (CRT-D). 
Table 2. Summary of the CRT Landmark Clinical Trials

Guideline
American College of Cardiology Foundation/
American Heart Association 2013, ESC
European Heart Rhythm Association 2013

National Institute of Health and Care Excellence (NICE) guidelines for ICD and CRT for arrhythmia and HF 2014

ESC Heart Failure Association guidelines for the diagnosis and treatment of acute and chronic HF 2016

Comprehensive update of the Canadian Cardiovascular Society guidelines for the management of heart failure 2017

\section{Recommendation}

CRT can be useful for patients who have LVEF less than or equal to $35 \%$, sinus rhythm, a non-LBBB pattern with a QRS duration greater than or equal to $150 \mathrm{~ms}$, and NYHA class III/ambulatory class IV symptoms on GDM. Class IIa, level of evidence A.

CRT may be considered for patients who have LVEF less than or equal to $35 \%$, sinus rhythm, a non-LBBB pattern with QRS duration 120 to $149 \mathrm{~ms}$, and NYHA class III/ambulatory class IV on GDM. Class IIb, level of evidence B.

CRT device insertion is indicated in patients with non-LBBB QRS morphology, who have QRS duration $\geq 150 \mathrm{~ms}$ and in NYHA functional classes II, III, and IV.

CRT pacemaker without ICD insertion is indicated in patients with non-LBBB QRS morphology who have a QRS between 120 and $149 \mathrm{~ms}$ and in NYHA functional class IV.

CRT should be considered for symptomatic patients with HF in sinus rhythm with QRS duration $\geq 150 \mathrm{~ms}$ and non-LBBB QRS morphology and with LVEF $\leq 35 \%$ despite OMT in order to improve symptoms and reduce morbidity and mortality. Class IIa, level of evidence B.

CRT may be considered for symptomatic patients with HF in sinus rhythm with QRS duration of 130 to $149 \mathrm{~ms}$ and non-LBBB QRS morphology and with LVEF $\leq 35 \%$ despite OMT in order to improve symptoms and reduce morbidity and mortality. Class $\mathrm{IIb}$, level of evidence B.

CRT may be considered for patients in sinus rhythm with NYHA class II, III, or ambulatory class IV HF despite optimal medical therapy, LVEF $\leq 35 \%$ and QRS duration $\geq 150 \mathrm{~ms}$ with non-LBBB (weak recommendation; low-quality evidence).

There is no clear evidence of benefit with CRT among patients with QRS durations $<150 \mathrm{~ms}$ because of non-LBBB conduction.

The table showed the summary of different international guidelines on indications of CRT in patients with non-LBBB wide QRS complex pattern. ESC: European Society of Cardiology; GDM: guideline-directed medical therapy; OMT: optical medical therapy; HF: heart failure; CRT: cardiac resynchronization therapy; NYHA: New York Heart Association; ICD: implantable cardioverter defibrillator; LBBB: left bundle branch block; RBBB: right bundle branch block.

In addition, NICE does not provide classes of recommendation or levels of evidence.

Finally, the guidelines published by the National Heart Foundation of Australia and the Cardiac Society of Australia and New Zealand in 2011, do not distinguish between LBBB and non-LBBB in their recommendations for CRT in patients in sinus rhythm. In Table 2, we summarize the different international guidelines of indications of CRT in patients with nonLBBB wide QRS complex.

\section{Evidence for CRT Efficacy in RBBB (Typical vs. Atypical RBBB Responders)}

Since the introduction of CRT in the treatment of patients with HF, an increasing number of patients with RBBB QRS morphology or long-drawn-out IVCD have been treated. The reason for that is QRS duration $\geq 120 \mathrm{~ms}$ had been considered initially as the only ECG selection criterion for CRT [26, 27]. Angelo et al recently reviewed the past observational studies that assessed the effect of CRT on some surrogate end points of mortality/morbidity and mortality directly. The results of two large US registries including patients with LBBB, IVCD, and RBBB were also included in the review. Neither the observational studies nor the meta-analysis demonstrated any significant benefit in CRT implant in patients with non-LBBB QRS complex pattern including typical RBBB. Moreover, the evidence of excess in mortality in RBBB CRT-treated patients than in LBBB CRT-treated patients is observed in both registries. The straightforward application of CRT in patients with typical RBBB was accordingly discouraged [28].

Although RBBB typically reflect delayed right ventricular (RV) activation, some patients with HF and RBBB pattern on ECG have concomitant superimposed delay in LV activation as well. RBBB commonly masks the underlying co-existent LBBB in broader QRS, the theory that was confirmed by electroanatomic mapping data, which demonstrated that not only RV activation is abnormally delayed but also LV activation delayed [29]. Rosenbaum et al [30] described atypical RBBB pattern as broad, slurred, sometimes bifid R wave on leads I and aVL, together with a leftward axis deviation frequently noted in LBBB QRS morphology patients (Fig. 2).

A recent review of several studies, that considered CRT in the subset of atypical RBBB, stated that acute response to CRT is clinically relevant and has positive values. Additional studies should be valued also as to whether a subset of patients with RBBB may benefit from CRT [28]. Subsequently, a study evaluated 66 patients with RBBB (31 with typical RBBB and 35 with atypical RBBB) treated with CRT and followed up for almost 2 years. The target end points of reduction in LV end- 


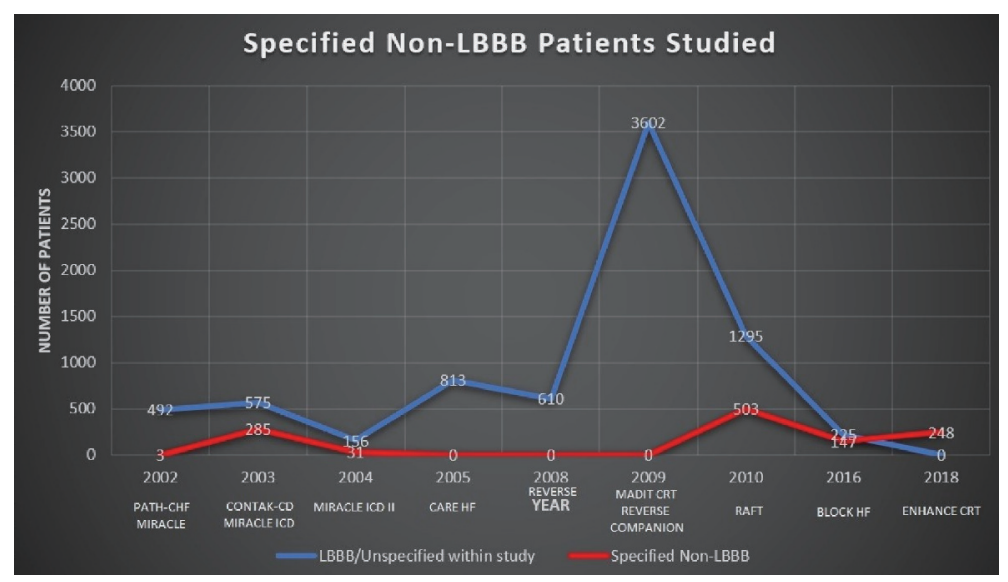

Figure 3. Line-graph representing the volume of patients studied over time, both LBBB/unspecified (blue) and specified nonLBBB (red). Only since 2016 can we see the gap beginning to narrow.

systolic volume index (ESVI) $\geq 15 \%$ or reduction in the NYHA class $\geq 1$ or Packer score variation (NYHA response with no HF-related hospitalization events or death) were considered. This showed $71.4 \%$ ESVI responders in atypical RBBB group in comparison with only $19.4 \%$ in typical RBBB group $(\mathrm{P}=0.001)$. Furthermore, $74.3 \%$ of patients in atypical RBBB group were NYHA responders compared with $32.3 \%$ in typical RBBB group $(\mathrm{P}=0.002)$. Similarly, in the atypical and typical RBBB groups, respectively $71.4 \%$ and $29.0 \%$ of patients exhibited a 2-year Packer score of $0(\mathrm{P}=0.002)$ [31].

We have represented the comparative number of patients studied with specified non-LBBB versus LBBB and unspecified groups in a line graph as shown in Figure 3. This graph clearly demonstrates the much greater numbers of subjects in the LBBB or unspecified IVCD arms of each study. We can see that only from 2016 onwards does the discrepancy of patients' numbers between the two begin to narrow and increase data for non-LBBB patients.

\section{Conclusions and Recommendations}

Non-LBBB (including atypical RBBB) in symptomatic HF patients may benefit from CRT implants. While the ESC task forces guidelines were directed towards symptomatic HF with $\mathrm{EF}<35 \%$ patients with broad QRS $>150 \mathrm{~ms}$ in non-LBBB patients, yet QRS 130 - 149 may respond with modest expectations of a good response. The American guidelines have the same considerations. However, it is clear that the Canadian guidelines still weakly support non-LBBB/CRT implants if QRS $>150 \mathrm{~ms}$, and in fact, it discourages CRT implants in QRS duration less than $150 \mathrm{~ms}$ in non-LBBB patients. Finally, NICE recommendation of non-LBBB with QRS 120 - 149 ms is only indicated in disabling HF (NYHA IV).

Non-LBBB CRT implants remain an area of debate. The previous support to CRT in those patients was on the basis of atypical features of RBBB and great IVCD. It remains a valid clinical decision to consider CRT implant in symptomatic patients (despite of optimized medical therapy) in non-LBBB with $\mathrm{QRS}$ duration $\geq 150 \mathrm{~ms}$. Multidisciplinary approaches (e.g. cardiac electrophysiologists, HF cardiologists, physiologist and specialists liaison HF nurses) and new techniques of multipoint pacing are promising in such difficult group of patients with debated indication and expected poor responders. The data are not encouraging in regards to typical RBBB with QRS duration less than $150 \mathrm{~ms}$.

\section{Acknowledgments}

None to declare.

\section{Financial Disclosure}

None to declare.

\section{Conflict of Interest}

\section{None to declare.}

\section{Author Contributions}

Maged Henin contributed to study design, manuscript writing and references check. Hany Ragy involved in manuscript review and re editing; James Mannion contributed to creating the tables of the major trials and edited the summary for each and language check. Santhosh David contributed to manuscript review and re-editing. Beshoy Refila contributed to study design, editing the manuscript and review. Usama Boles, the main supervisor, involved in study design, review, editing, and pre-submission check.

\section{References}

1. Yancy CW, Jessup M, Bozkurt B, Butler J, Casey DE, 
Jr., Colvin MM, Drazner MH, et al. 2017 ACC/AHA/ HFSA Focused Update of the 2013 ACCF/AHA Guideline for the Management of Heart Failure: A Report of the American College of Cardiology/American Heart Association Task Force on Clinical Practice Guidelines and the Heart Failure Society of America. J Am Coll Cardiol. 2017;70(6):776-803.

2. Ezekowitz JA, O'Meara E, McDonald MA, Abrams H, Chan M, Ducharme A, Giannetti N, et al. 2017 Comprehensive Update of the Canadian Cardiovascular Society Guidelines for the Management of Heart Failure. Can J Cardiol. 2017;33(11):1342-1433.

3. Al-Majed NS, McAlister FA, Bakal JA, Ezekowitz JA. Meta-analysis: cardiac resynchronization therapy for patients with less symptomatic heart failure. Ann Intern Med. 2011;154(6):401-412.

4. Wells G, Parkash R, Healey JS, Talajic M, Arnold JM, Sullivan S, Peterson J, et al. Cardiac resynchronization therapy: a meta-analysis of randomized controlled trials. CMAJ. 2011;183(4):421-429.

5. Woods B, Hawkins N, Mealing S, Sutton A, Abraham WT, Beshai JF, Klein H, et al. Individual patient data network meta-analysis of mortality effects of implantable cardiac devices. Heart. 2015;101(22):1800-1806.

6. Goldenberg I, Kutyifa V, Klein HU, Cannom DS, Brown MW, Dan A, Daubert JP, et al. Survival with cardiac-resynchronization therapy in mild heart failure. N Engl J Med. 2014;370(18):1694-1701.

7. Ponikowski P, Voors AA, Anker SD, Bueno H, Cleland JG, Coats AJ, Falk V, et al. 2016 ESC Guidelines for the diagnosis and treatment of acute and chronic heart failure: The Task Force for the diagnosis and treatment of acute and chronic heart failure of the European Society of Cardiology (ESC). Developed with the special contribution of the Heart Failure Association (HFA) of the ESC. Eur J Heart Fail. 2016;18(8):891-975.

8. Colquitt JL, Mendes D, Clegg AJ, Harris P, Cooper K, Picot J, Bryant J. Implantable cardioverter defibrillators for the treatment of arrhythmias and cardiac resynchronisation therapy for the treatment of heart failure: systematic review and economic evaluation. Health Technol Assess. 2014;18(56):1-560.

9. Epstein AE, DiMarco JP, Ellenbogen KA, Estes NA, 3rd, Freedman RA, Gettes LS, Gillinov AM, et al. 2012 ACCF/ AHA/HRS focused update incorporated into the ACCF/ AHA/HRS 2008 guidelines for device-based therapy of cardiac rhythm abnormalities: a report of the American College of Cardiology Foundation/American Heart Association Task Force on Practice Guidelines and the Heart Rhythm Society. J Am Coll Cardiol. 2013;61(3):e6-75.

10. Brignole M, Auricchio A, Baron-Esquivias G, Bordachar P, Boriani G, Breithardt OA, Cleland J, et al. 2013 ESC Guidelines on cardiac pacing and cardiac resynchronization therapy: the Task Force on cardiac pacing and resynchronization therapy of the European Society of Cardiology (ESC). Developed in collaboration with the European Heart Rhythm Association (EHRA). Eur Heart J. 2013;34(29):2281-2329.

11. Krum H, Jelinek MV, Stewart S, Sindone A, Atherton JJ,
National Heart Foundation of A, Cardiac Society of A, et al. 2011 update to National Heart Foundation of Australia and Cardiac Society of Australia and New Zealand Guidelines for the prevention, detection and management of chronic heart failure in Australia, 2006. Med J Aust. 2011;194(8):405-409.

12. Surawicz B, Childers R, Deal BJ, Gettes LS, Bailey JJ, Gorgels A, Hancock EW, et al. AHA/ACCF/HRS recommendations for the standardization and interpretation of the electrocardiogram: part III: intraventricular conduction disturbances: a scientific statement from the American Heart Association Electrocardiography and Arrhythmias Committee, Council on Clinical Cardiology; the American College of Cardiology Foundation; and the Heart Rhythm Society: endorsed by the International Society for Computerized Electrocardiology. Circulation. 2009;119(10):e235-240.

13. Auricchio A, Stellbrink C, Sack S, Block M, Vogt J, Bakker P, Huth C, et al. Long-term clinical effect of hemodynamically optimized cardiac resynchronization therapy in patients with heart failure and ventricular conduction delay. J Am Coll Cardiol. 2002;39(12):2026-2033.

14. Abraham W, Fisher W, Smith A. Cardiac resynchronization in chronic heart failure. ACC Current Journal Review. 2002;11(6):75.

15. Higgins SL, Hummel JD, Niazi IK, Giudici MC, Worley SJ, Saxon LA, Boehmer JP, et al. Cardiac resynchronization therapy for the treatment of heart failure in patients with intraventricular conduction delay and malignant ventricular tachyarrhythmias. J Am Coll Cardiol. 2003;42(8):1454-1459.

16. Young JB, Abraham WT, Smith AL, Leon AR, Lieberman R, Wilkoff B, Canby RC, et al. Combined cardiac resynchronization and implantable cardioversion defibrillation in advanced chronic heart failure: the MIRACLE ICD Trial. JAMA. 2003;289(20):2685-2694.

17. Abraham WT, Young JB, Leon AR, Adler S, Bank AJ, Hall SA, Lieberman R, et al. Effects of cardiac resynchronization on disease progression in patients with left ventricular systolic dysfunction, an indication for an implantable cardioverter-defibrillator, and mildly symptomatic chronic heart failure. Circulation. 2004;110(18):28642868.

18. Cleland JG, Daubert JC, Erdmann E, Freemantle N, Gras D, Kappenberger L, Tavazzi L, et al. The effect of cardiac resynchronization on morbidity and mortality in heart failure. N Engl J Med. 2005;352(15):1539-1549.

19. Linde C, Abraham WT, Gold MR, St John Sutton M, Ghio S, Daubert C, REVERSE (REsynchronization reVErses Remodeling in Systolic left vEntricular dysfunction) Study Group. Randomized trial of cardiac resynchronization in mildly symptomatic heart failure patients and in asymptomatic patients with left ventricular dysfunction and previous heart failure symptoms. J Am Coll Cardiol. 2008;52(23):1834-1843.

20. Breithardt G. MADIT-CRT (Multicenter Automatic Defibrillator Implantation Trial-Cardiac Resynchronization Therapy): cardiac resynchronization therapy towards early management of heart failure. Eur Heart J. 
2009;30(21):2551-2553.

21. Daubert C, Gold MR, Abraham WT, Ghio S, Hassager C, Goode G, Szili-Torok T, et al. Prevention of disease progression by cardiac resynchronization therapy in patients with asymptomatic or mildly symptomatic left ventricular dysfunction: insights from the European cohort of the REVERSE (Resynchronization Reverses Remodeling in Systolic Left Ventricular Dysfunction) trial. J Am Coll Cardiol. 2009;54(20):1837-1846.

22. Anand IS, Carson P, Galle E, Song R, Boehmer J, Ghali JK, Jaski B, et al. Cardiac resynchronization therapy reduces the risk of hospitalizations in patients with advanced heart failure: results from the Comparison of Medical Therapy, Pacing and Defibrillation in Heart Failure (COMPANION) trial. Circulation. 2009;119(7):969977.

23. Tang AS, Wells GA, Talajic M, Arnold MO, Sheldon R, Connolly S, Hohnloser SH, et al. Cardiac-resynchronization therapy for mild-to-moderate heart failure. N Engl J Med. 2010;363(25):2385-2395.

24. Curtis AB, Worley SJ, Chung ES, Li P, Christman SA, St John Sutton M. Improvement in Clinical Outcomes With Biventricular Versus Right Ventricular Pacing: The BLOCK HF Study. J Am Coll Cardiol. 2016;67(18):21482157.

25. Singh JP, Berger RD, Doshi RN, Lloyd M, Moore D, Daoud EG, for the ENHANCE CRT Study Group. Rationale and design for ENHANCE CRT: QLV implant strategy for non-left bundle branch block patients. ESC Heart Fail. 2018;5(6):1184-1190.

26. Hara H, Oyenuga OA, Tanaka H, Adelstein EC, Onishi T, McNamara DM, Schwartzman D, et al. The relationship of QRS morphology and mechanical dyssynchrony to long-term outcome following cardiac resynchronization therapy. Eur Heart J. 2012;33(21):2680-2691.
27. Kandala J, Upadhyay GA, Altman RK, Parks KA, Orencole M, Mela T, Kevin Heist E, et al. QRS morphology, left ventricular lead location, and clinical outcome in patients receiving cardiac resynchronization therapy. Eur Heart J. 2013;34(29):2252-2262.

28. Auricchio A, Lumens J, Prinzen FW. Does cardiac resynchronization therapy benefit patients with right bundle branch block: cardiac resynchronization therapy has a role in patients with right bundle branch block. Circ Arrhythm Electrophysiol. 2014;7(3):532-542.

29. Fantoni C, Kawabata M, Massaro R, Regoli F, Raffa S, Arora V, Salerno-Uriarte JA, et al. Right and left ventricular activation sequence in patients with heart failure and right bundle branch block: a detailed analysis using threedimensional non-fluoroscopic electroanatomic mapping system. J Cardiovasc Electrophysiol. 2005;16(2):112119; discussion 120-111.

30. Rosenbaum MB, Yesuron J, Lazzari JO, Elizari MV. Left anterior hemiblock obscuring the diagnosis of right bundle branch block. Circulation. 1973;48(2):298-303.

31. Pastore G, Morani G, Maines M, Marcantoni L, Bolzan B, Zanon F, Noventa F, et al. Patients with right bundle branch block and concomitant delayed left ventricular activation respond to cardiac resynchronization therapy. Europace. 2018;20(11):e171-e178.

32. Relias media, K.G. Internal Medicine Alert. [Online]. 2019. Available from: https://www.reliasmedia.com.

33. Ferry DR. ECG in 10 days. United States of America: McGraw-Hill Companies, Inc. 2007.

34. Drezner JA, Fischbach P, Froelicher V, Marek J, Pelliccia A, Prutkin JM, Schmied CM, et al. Normal electrocardiographic findings: recognising physiological adaptations in athletes. Br J Sports Med. 2013;47(3):125-136.

35. Yanowitz FG. ECG Learning centre. [Online]. 2019. Available from: https://ecg.utah.edu/lesson/6\#RBBB. 